\title{
Express method of injection well treatment
}

\author{
M. Ya. Khabibullin \\ Ufa State Petroleum Technological University \\ Branch of the University in the City of Oktyabrsky \\ Oktyabrsky, Russian Federation \\ E-mail: $\underline{\text { m-hab@ mail.ru }}$
}

\author{
R. I. Suleimanov \\ Ufa State Petroleum Technological University \\ Branch of the University in the City of Oktyabrsky \\ Oktyabrsky, Russian Federation \\ E-mail: $\underline{\text { m-hab@mail.ru }}$
}

\author{
E. R. Vasilyeva \\ Ufa State Petroleum Technological University \\ Branch of the University in the City of Oktyabrsky \\ Oktyabrsky, Russian Federation \\ E-mail: m-hab@mail.ru
}

\begin{abstract}
During water injection in the bottomhole zone, except corrosion products, which are the main plugging agent, mechanical particles containing in the injected water are collected. They form a sediment that pollutes the filtration channels of the formation, gradually reducing the absorption capacity of the injection well. In order to inject as much water into the formation as it's possible during the planning period, it is necessary to carry out repairs in a well with the help of one-time mud-pulse treatments. The introduction of this express method of treatment allowed reducing the material costs significantly and maintaining a stable level of injection and a stable coefficient of selection.
\end{abstract}

Keywords-overhaul period; injection capacity; water injection well; treatment; repair

\section{INTRODUCTION}

When flooding production zone, built up by tight sandstones, the bottom-hole zone of injection wells is grouted with mechanical impurities brought into the formation by injected water within definite time. As a consequence, the injection wells gradually reduce the injection capacity, which adversely affects the injection balance. To restore the injection capacity of a well, the following methods are used: drained acid formation treatment, hydraulic fracturing, hydraulic acid treatment without sand cracks fixing, thermal treatment of formation, mud-pulse one-time treatment, draw-down pressure, shot-firing operations, etc [1-13].

However, it should be noted that these technical measures are very hard and expensive for implementing. Performing of these works for a long time causes a continuous cease of water injection and withdrawal of a significant amount of previously injected water from the reservoir.

\section{MATERIALS AND METHODS}

At the Stakhanovskoye field of the NGDU «Oktyabrskneft», NK «Bashneft», to restore the injection capacity of wells, which were for a long time under injection, one-time mud-pulse bottomhole treatments were performed (Table 1) [1]. After acidizing job, without reducing the pressure at the wellhead, water injection through the water pipe is immediately resumed, which allows processed products to be taken to a remote zone of the formation. A similar technology for water-injection well repairing was also used in the oil fields of OAO «Tatnefteprom». However, the analysis of the data obtained showed that these treatments cannot be carried out indefinitely, since the efficiency of subsequent treatments is usually reduced (Table 1).

During water injection in the bottomhole zone, in addition to corrosion products, which are the main sealing agent, mechanical particles in the injected water accumulate. They form residue that pollutes the filtration channels of the formation, gradually reducing the absorbing capacity of the injection well.

To determine the maximum water injection into the formation during mud-pulse treatments in the period between two well repairs and the number of repairs, let's assume that the first repair of the injection well was carried out at the beginning of the considered period $T$. After repair, it was put into operation with an initial injection capacity $\mathrm{q}_{0}$, cub. $\mathrm{m} /$ day. Subsequently, its injection capacity fell according to the law: [2]

$$
q=q_{0} \cdot e^{\frac{t}{t_{0}} \ln \beta},
$$

where $t-$ well operation time during the time between overhauls, a day;

$t_{0}$-time, during which well injection capacity becomes equal to $\beta \cdot q_{0}$ (according to the field data), a day;

$\beta$ - the relation of well injection capacity in the moment $t_{0}$ to the injection capacity $q_{0}$. 
TABLE I. THE APPLICATION OUTCOMES OF ONE-TIME MUD-PULSE TREATMENTS IN THE INJECTION WELLS OF THE FIELDS OF OAO “TATNEFTEPROM”

\begin{tabular}{|c|c|c|c|c|c|}
\hline \multirow[t]{2}{*}{$\begin{array}{c}\text { Well } \\
\text { number }\end{array}$} & \multirow{2}{*}{$\begin{array}{l}\text { Injection capacity } \\
\text { before treatment, cub. } \\
\text { m/day }\end{array}$} & \multirow{2}{*}{$\begin{array}{c}\text { Injection } \\
\text { pressure, } \\
\text { МРa }\end{array}$} & \multicolumn{3}{|c|}{$\begin{array}{l}\text { Injection capacity before treatment in } \\
\text { (cub. } \mathrm{m} / \text { day) }\end{array}$} \\
\hline & & & $\begin{array}{l}10 \text { natural } \\
\text { days }\end{array}$ & $\begin{array}{l}20 \text { natural } \\
\text { days }\end{array}$ & $\begin{array}{l}30 \text { natural } \\
\text { days }\end{array}$ \\
\hline 6513 & 120 & 8 & 260 & 240 & 210 \\
\hline 6646 & 80 & 8 & 190 & 180 & 160 \\
\hline 6780 & 110 & 8 & 220 & 200 & 185 \\
\hline 7223 & 50 & 8 & 110 & 100 & 65 \\
\hline 7704 & 60 & 8 & 140 & 135 & 110 \\
\hline 7821 & 90 & 8 & 230 & 235 & 210 \\
\hline 8432 & 65 & 8 & 180 & 170 & 150 \\
\hline 8640 & 85 & 8 & 145 & 140 & 130 \\
\hline 8784 & 105 & 8 & 280 & 220 & 200 \\
\hline 9629 & 75 & 8 & 170 & 160 & 130 \\
\hline
\end{tabular}

In order to inject the most possible quantity of water during the target period $T$, it is necessary to conduct the repair in a well with the help of one-time mud-pulse treatments. It is known that it is possible to conduct not more $\mathrm{N}$ treatment in a well during the target period $T$. Suppose that after each $\mathrm{j}$ treatment in the bottomhole zone the well injection capacity is defined by: [2]

$$
q_{o j}=a+b t_{j},
$$

where multiplying factors $\mathrm{a}$ and $\mathrm{b}$ should be defined providing that:

$$
q_{o j}=q_{0} \text { at } t_{j}=\tau ; q_{o j}=\alpha q_{0} \text { at } t_{j}=t_{k},
$$

where $\tau$-time of repair, a day;

$t_{k}$ - time at which the proportionality factor a is defined, a day.

\section{RESULTS AND DISCUSSIONS}

It is necessary to determine how many repairs it is necessary to carry out in the well in order to pump the maximum possible amount of water into the reservoir during the target period $T$.

In this case, the mathematical problem comes down to determining of the total injection: [3]

$V=n\left\{\begin{array}{l}-\frac{q_{0} \cdot t_{0}}{\ln \beta}\left[1+m\left(\frac{t_{k}-\alpha \cdot \tau}{t_{k}-\tau}-\frac{1-\alpha}{t_{k}-\tau}\left(\frac{\tau+t_{p}}{2}\right)\right)\right] \times \\ \times\left(1-e^{\frac{t_{p} \cdot \ln \beta}{(m+1) t_{0}}}\right)-q_{0} \cdot \tau\end{array}\right\}$

under conditions:

$$
n\left(t_{p}+\tau\right)=T,
$$

$$
n(v+m) \leq N,
$$

where $n$ - is the number of repairs;

$t_{p}$ - overhaul period of the well performance, a day;

$m$ - is the number of one-time mud-pulse treatments that can be carried out during a single overhaul period $t_{p}$;

$v$ - is the total number of one-time mud-pulse treatments.

If we assume that the total expenditures for all repairs and mud-pulse treatments should not exceed $S$ dollars, then the solution of the problem can be limited to one more condition [3]:

$$
n\left(C_{p}+m C_{n}\right) \leq S
$$

where $C_{p}, C_{n}-$ one repair and one-time mud-pulse treatment cost, dollar.

In this case the problem reduces to determining the maximum of the function (4), but under the conditions (5), (6) and (7).

Suppose that it is necessary to determine how many repairs and mud-pulse treatments should be carried out in each of $\mathrm{M}$ injection wells of the oil field, in order to make the total water injection maximum. Presuming that the problem formulated above is valid for the well $i$ of the group under consideration, so the mathematical problem for this group reduces to determining the maximum of the total problem [3]

$\sigma=\sum_{i=1}^{M} V_{i}=\sum_{i=1}^{M}\left\{\begin{array}{l}\frac{q_{o i} t_{o i}}{\ln \beta}\left[1+m_{i}\left(\frac{t_{k i}-\alpha \cdot \tau_{i}}{t_{k i}-\tau_{i}}-\frac{1-\alpha_{i}}{t_{k i}-\tau_{i}} \frac{t_{p i}}{2}\right)\right] \times \\ \times\left(1-e^{\frac{t_{p i p} \cdot \ln \beta_{i}}{\left(m_{i}+1\right) t_{o i}}}\right)-q_{o i} \tau_{i}\end{array}\right\} n_{i}$,

under conditions: 


$$
\begin{gathered}
n_{i}\left(t_{p i}+\tau_{i}\right)=T, \quad i=1,2,3, \ldots, M \\
\sum_{i=1}^{M} n_{i}\left(v_{i}+m_{i}\right) \leq N \\
\sum_{i=1}^{M} n_{i}\left(C_{p i}+m_{i} C_{k i}\right) \leq S
\end{gathered}
$$

Calculation data for determining the total water injection into the well 9629 (Table 2) allowed graphically ( Figure1) to study the limits and boundaries of the optimal conditions selection (area) of one-time mud-pulse treatments.

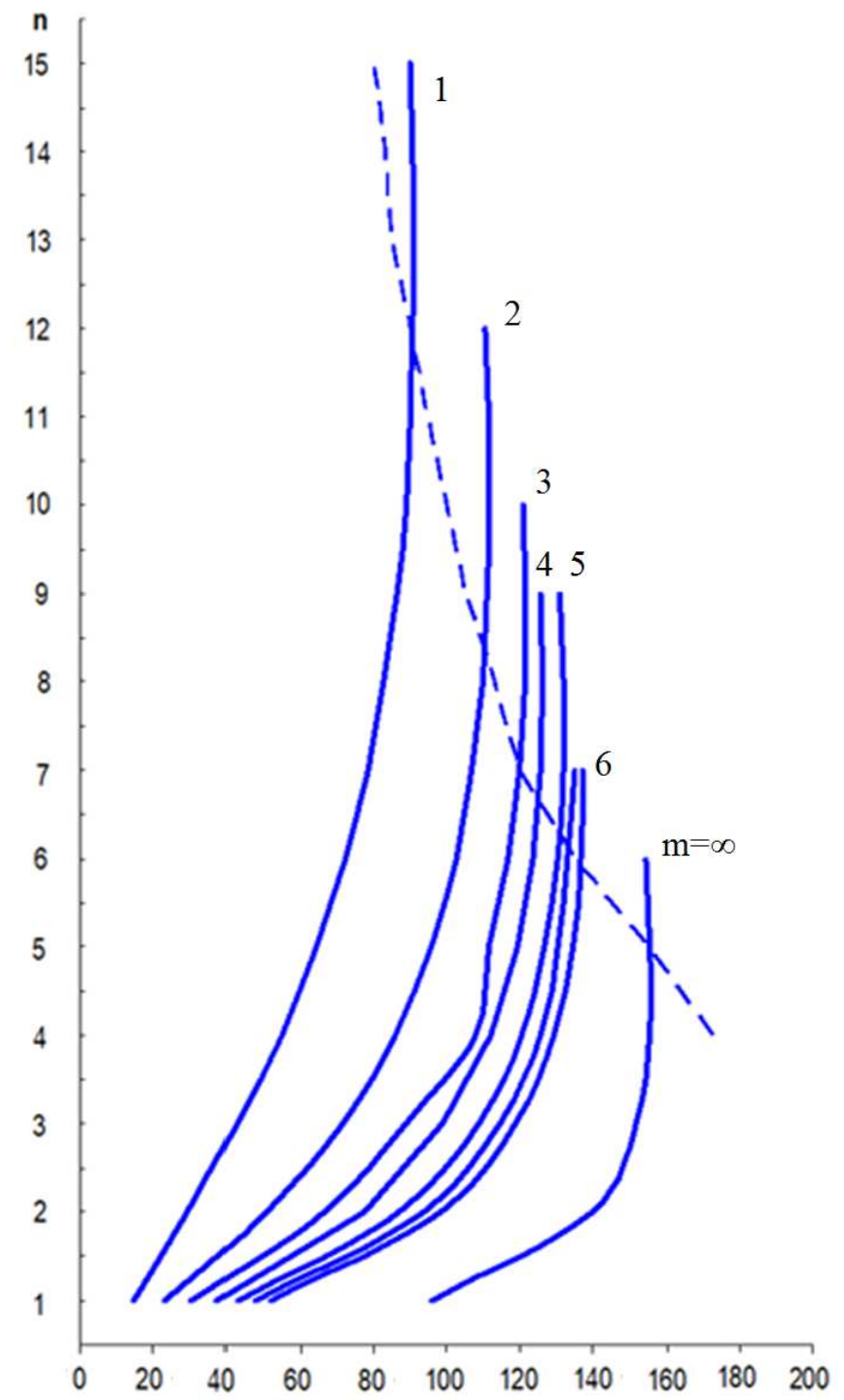

Fig. 1. Graphic charts of the total fluid injection $V=f(n, m)$ for the injection well 9629

\section{CONCLUSION}

1. The parabolical arrangement of the curves $V=f(n, m)$ makes it possible to distinguish the area of optimal conditions for the use of one-time mud-pulse treatments.

2. The area of optimal conditions (Figure 1, dotted graph) expresses the increase in the number of repairs $n$ with the decrease in the total volume of injected water, while the increase in mud-pulse treatments $m$ leads to a rather noticeable increase in the total water absorption.

3. The maximum total water injection can be achieved by the infinite carrying out of mud-pulse treatments. However, this option (variation) is irrational in conditions of a considerable length of water lines, because corrosion products along the entire length of the pipelines will be injected to the bottomhole zone.

4. The best conditions for maintaining the stable operation processes of the studied injection wells are shown at $m=5$ and $n=7$, resulting in the total water injection of $134985 \mathrm{~m}^{3}$. The same cannot be said for those optimum points, which are located above and below the selected point of the injection well operating mode. This is explained by the following:

- the low points of optima on parabolic curves tend to decrease the total injection;

- the upper point obtained when $m=\infty$ is certainly the most advantageous theoretically, but it is very difficult to achieve it practically.

Therefore, the most advantageous regime should be considered as one that can be achieved in the zone of approximation of the value $m$ to the conditions of infinity. Such a regime, as can be seen from Figure 1, to the greatest extent meets the point at which $m=5$, since the difference between the values $V$ at points $m=\infty$ and $m=5$ is calculated with a tenuous limit of $20756 \mathrm{~m}^{3}$.

5. A similar problem was considered for groups of simultaneously operating injection wells.

6. The use of one-time mud-pulse treatments by express method made it possible to reduce material expenses significantly and maintain a stable level of injection and a percent of oil recovery, which enabled only with 16 treatments to save about $\$ 45.000$. 
TABLE II.

TOTAL INJECTION $\left(\mathrm{M}^{3}\right)$ ACCORDING TO CALCULATIONS FOR THE WELL 9629 (OAO “TATNEFTEPROM”)

\begin{tabular}{|c|c|c|c|c|c|c|c|c|}
\hline \multirow{2}{*}{$\begin{array}{c}\text { Num- } \\
\text { ber of } \\
\text { repair } \\
\mathbf{s , n} \boldsymbol{n}\end{array}$} & $\mathbf{0}$ & $\mathbf{1}$ & $\mathbf{2}$ & $\mathbf{3}$ & $\mathbf{4}$ & $\mathbf{5}$ & $\mathbf{6}$ & $\begin{array}{c}\text { Acid water } \\
\text { injecting, } \\
\mathbf{~}^{\mathbf{3}}\end{array}$ \\
\cline { 2 - 9 } & & & & & & & & \\
\hline 1 & 14646 & 22790 & 30442 & 37090 & 42930 & 47540 & 51919 & 95998 \\
\hline 2 & 29199 & 50691 & 66629 & 77609 & 86700 & 93572 & 98375 & 140037 \\
\hline 3 & 42866 & 71565 & 89200 & 98766 & 108686 & 114799 & 119019 & 151783 \\
\hline 4 & 54772 & 86030 & 108078 & 112226 & 120405 & 125682 & 129228 & 155475 \\
\hline 5 & 64539 & 95947 & 111644 & 119452 & 126936 & 130548 & 134388 & 155741 \\
\hline 6 & 72313 & 102560 & 116858 & 123421 & 130303 & 133106 & 136635 & 154509 \\
\hline 7 & 78320 & 107041 & 119952 & 125409 & 131679 & 134985 & 137221 & - \\
\hline 8 & 82904 & 109764 & 121363 & 125981 & 131747 & 134685 & 136587 & - \\
\hline 9 & 86207 & 111192 & 121618 & 125568 & 131008 & 133454 & 134256 & - \\
\hline 10 & 88750 & 111639 & 121164 & 124386 & 129508 & 131738 & 133245 & - \\
\hline 11 & 90234 & 111461 & 119560 & 122875 & 127498 & 129940 & 130719 & - \\
\hline 12 & 90812 & 110661 & 118286 & 120741 & 125123 & 126931 & 128202 & - \\
\hline 13 & 91294 & 109306 & 116276 & 119051 & 122464 & 124139 & 125246 & - \\
\hline 14 & 90663 & 107620 & 114241 & 115717 & 119621 & 121110 & 122082 & - \\
\hline 15 & 89889 & 105530 & 111657 & 112719 & 116531 & 117877 & 118745 & - \\
\hline & & & & & & & & \\
\hline
\end{tabular}

\section{References}

[1] M. Ya. Habibullin and D. I. Sidorkin, "Determination of Tubing String Vibration Parameters under Pulsed Injection of Fluids into the Well," SOCAR Proceedings, vol. 3, pp.27-32, 2016. https://doi.org/10.5510/ogp20160300285

[2] M. Ya. Khabibullin, R. I. Suleimanov, D. I. Sidorkin and I G. Arslanov, "Parameters of Damping of Vibrations of Tubing String in the Operation of Bottomhole Pulse Devices," Chem Petrol Eng, vol. 53, pp. 378-384, 2017. https://doi.org/10.1007/s10556-017-0350-6

[3] Korn G A, Korn T M. Mathematical Handbook for Scientists and Engineers: Definitions, Theorems, and Formulas for Reference and Review. Moscow: Nauka, 1984.

[4] R.M. Shaidullina, A.F. Amirov, V.S. Muhametshin and K.T. Tyncherov, "Designing economic socialization system in the educational process of technological university," European Journal of Contemporary
Education, Vol. 6 (1), pp. 149-158, 2017. DOI: 10.13187/ejced.2017.1.1494

[5] N.Y. Golovina, L.G. Akhmetov, A.N. Vikharev and I.G. Arslanov, "Analysis on compressor blading conditions of helicopter's gas-Turbine engine working in polluted environment," International Journal of Applied Engineering Research, vol. 12, pp. 293-296, 2017

[6] G.R. Igtisamova and N.O. Kovalev "Reliability evaluation for improved screw dies of coiled tubing unit injector," Tribology in Industry, vol. 39, pp. 45-49, 2017.

[7] M.V. Goryunova, L.S. Kuleshova and A.I. Khakimova, "Application of signal analysis for diagnostics," International Conference on Industrial Engineering, Applications and Manufacturing (ICIEAM) (Saint Petersburg, 16-19 May 2017), SPb.: IEEE, 2017. DOI: 10.1109/ICIEAM.2017.8076487

[8] V.V. Mukhametshin, "Efficiency estimation of nanotechnologies applied in constructed wells to accelerate field development," Nanotechnologies in Construction, vol. 10, no. 1, pp. 113-131, 2018. DOI: 10.15828/20758545-2018-10-1-113-131

[9] K.T. Tyncherov, V.Sh. Mukhametshin and L.B. Khuzina, "Method to Control and Correct Telemetry Well Information in the Basis of Residue Number System," Journal of Fundamental and Applied Sciences, vol. 9, no. (2S), pp. 1370-1374, 2017. DOI: 10.4314/jfas.v9i2s. 848

[10] G.A. Teptereva, G.V. Konesev, R.A. Ismakov, E.A. Kantor and T.D. Dikhtyar, "Obtaining drill reagents by modification of neutral-sulphite alkali phosphonic compounds," Bulletin of the Tomsk Polytechnic University, Geo Assets Engineering, vol. 328, pp. 94-101, 2017.

[11] L.A. Kovaleva, R.Z. Minnigalimov, R.R. Zinnatullin, V.N. Blagochinnov and A.I. Mullayanov, "Study of integrated effects microwave electromagnetic radiation in the field of centrifugal forces on the water-oil emulsion," Neftyanoe Khozyaystvo - Oil Industry, vol.2, pp. 100-102, 2017.

[12] A. Davletbaev, V. Kireev, L. Kovaleva, A. Zainullin, R. Minnigalimov, "Cold heavy oil production and production by radio-frequency electromagnetic radiation: Comparative numerical study," AIP Conference Proceedings International Conference of Computational Methods in Sciences and Engineering, ICCMSE 2016, vol. 1790, pp. 150021,2016

V.N. Polyakov, Yu.V. Zeigman, Yu.A. Kotenev, V.V. Mukhametshin, Sh.Kh. Sultanov and A.P. Chizhov, "System solution for technological problems of well construction completion," Nanotechnologies in Construction, vol. 10 , no. 1 , pp. $72-87$, 2018. DOI: $10.15828 / 2075-$ 8545-2018-10-1-72-87 